\title{
Assessing the role of thermal disequilibrium in the evolution of the lithosphere-asthenosphere boundary: An idealized model of heat exchange during channelized melt-transport
}

\author{
Mousumi Roy ${ }^{1}$ \\ ${ }^{1}$ Department of Physics and Astronomy, University of New Mexico, Albuquerque, NM 87106, USA \\ Correspondence: Mousumi Roy (mroy@unm.edu)
}

\begin{abstract}
This study explores how the continental lithospheric mantle (CLM) may be heated during channelized melt transport when there is thermal disequilibrium between (melt-rich) channels and surrounding (melt-poor) regions. Specifically, I explore the role of disequilibrium heat exchange in weakening and destabilizing the lithosphere from beneath as melts infiltrate into the lithosphere-asthenosphere boundary (LAB). During equilibration, hotter-than-ambient melts would be expected

5 to heat the surrounding CLM, but we lack an understanding of the expected spatio-temporal scales and how these depend on channel geometries, infiltration duration, and transport rates. This study utilizes a 1D model of thermal disequilibrium between melt-rich channels and the surrounding melt-poor region, parameterized by the volume fraction of channels $(\phi)$, relative velocity across channel walls ( $\left.v_{\text {channel }}\right)$, channel spacing $(d)$, and timescale of episodic melt-infiltration $(\tau)$. The results suggest that, during episodic infiltration of hotter-than-ambient melt, a steady-state thermal reworking zone (TRZ) associated with spatio-temporally varying disequilibrium heat exchange forms at the LAB. The TRZ grows by the transient migration of a disequilibrium-heating front at a material-dependent velocity, reaching a maximum steady-state width $\delta \sim\left[\phi v_{\text {channel }}(\tau / d)^{2}\right]$. The spatio-temporal scales associated with establishment of the TRZ are comparable with those inferred for the migration of the LAB based on geologic observations within continental intra-plate settings, such as the western US. For geologicallyreasonable values of $\phi, v_{\text {channel }}, d$, and $\tau$, disequilibrium heating within the TRZ may contribute at least $10^{-3} \mathrm{~W} / \mathrm{m}^{3}$ to the
\end{abstract} LAB heat budget.

\section{Scientific Motivation}

During its long residence at Earth's surface, continental lithosphere is shaped by tectonic events such as rifting (including supercontinent break-up) and plate collision, undergoing profound changes in its physical and chemical state. In some cases, previously stable (undeforming) portions of the continental lithosphere may be destabilized. Based on the close association of magma infiltration with these events there is growing speculation that, under certain circumstances, melt-rock interaction may somehow weaken and perturb the stability of continental lithosphere (Hopper et al., 2020; Wenker and Beaumont, 2017; Plank and Forsyth, 2016; Roy et al., 2016; Wang et al., 2015; Menzies et al., 2007; Carlson et al., 2004; Gao et al., 2002; O'Reilly et al., 2001). Fundamentally, this melt-enhanced weakening of continents is intertwined with the notion of thermal and chemical disequilibrium between infiltrating melts and the surrounding material, and therefore with transient processes that 
https://doi.org/10.5194/se-2022-13

Preprint. Discussion started: 17 February 2022

(c) Author(s) 2022. CC BY 4.0 License.

\section{(c) (1)}

drive the lithosphere from one stable state to another. These processes, however, remain elusive. This paper explores one aspect of the problem, namely, thermal disequilibrium during infiltration of hotter-than-ambient melts into the base of the lithosphere, as a means of weakening and shaping the continental lithosphere from beneath. Specifically, I explore thermal disequilibrium between melt-rich channels and surrounding (melt-poor) material as a process to heat and modify the continental lithospheric mantle (CLM). The models explored here are a useful way to place constraints on the melt-transport scenarios for which a significant degree of disequilibrium heat exchange may be important in the CLM at or near the lithosphere-asthenosphere boundary (LAB).

This study is inspired by evidence for the role of thermal disequilibrium from detailed field-based, petrologic, and geochemical studies in the Lherz and Ronda peridotite massifs (e.g., Soustelle et al., 2009; LeRoux et al., 2007, summarized in Appendix A). I build on the idea that melt-rock interaction in the lower CLM may be characterized by zones with steep, transient thermal gradients as observed in these massifs (e.g., Soustelle et al., 2009, Appendix A). Additionally, this work is motivated by observations from the western US, which has undergone extensive magma-infiltration in Cenozoic time. Pressures and temperatures of last equilibration of Cenozoic basalts consistently point to depths that are at or below the LAB (Plank and Forsyth, 2016), suggesting that melt transport from those depths upward through the lower CLM occurs in thermal disequilibrium. In the Big Pine volcanic field, for example, the inferred depth of the LAB decreases by $>10 \mathrm{~km}$ in a timespan of $<1$ Myr (Plank and Forsyth, 2016), suggesting that the processes associated with this migration may be transient (LAB vertical migration rates in excess of $\sim 10 \mathrm{~km} / \mathrm{Myr}$ ). More recently, Cenozoic melt- or fluid-enhanced thinning of the CLM in the western US has also been inferred from geochemical and isotopic data from volcanic rocks (Farmer et al., 2020). Motivated by these observations, a primary goal of this work is to quantify the role of transient, disequilibrium heating by infiltrating channelized melt as a mechanism for modifying the LAB and the lowermost CLM.

A permeability contrast (e.g., Holtzman and Kendall, 2010) or a change in magma mobility (e.g., Sakamaki et al., 2013) across the LAB is likely to drive melts to pond at the LAB and possibly drive the upward propagation of dikes that may freeze and heat the CLM (e.g., Havlin et al., 2013). Not all infiltrating melts would freeze, however, and some component of hotter-than-ambient melts may be transported in thermal and chemical disequilibrium into the CLM via established channels/pathways (e.g., LeRoux et al., 2007; Schmeling et al., 2018). Thermal disequilibrium during melt transport is expected to become important within the CLM as the degree of channelization and the relative melt-solid velocity increases (e.g., Schmeling et al., 2018). In this work, I am not concerned with the development of these channel networks within the lower CLM, nor the deeper processes that transport melt from a sub-lithospheric melt-generation zone (e.g., Aharonov et al., 1995). Instead, the starting point of this study is the observation that high-porosity, melt-rich channels are an important part of melt-rock interaction in the CLM (e.g. Soustelle et al., 2009; LeRoux et al., 2007). Therefore, I focus on the implications of significant thermal gradients between melt-rich channels and their surroundings. Although others have also argued for the important role of thermal disequilibrium in melt-rock interaction (Keller and Suckale, 2019; Wallner and Schmeling, 2016; Schmeling et al., 2018), this study provides a quantification of the role of thermal disequilibrium at the LAB based on observational constraints discussed above (also Appendix A). 
This work abstracts the complex geometry of the melt-rock interface and therefore differs from other descriptions of disequilibrium heat exchange (Wallner and Schmeling, 2016; Schmeling et al., 2018; Keller and Suckale, 2019). Similar to chemical transport models that use a linear driving term for chemical disequilibrium (e.g., Hauri, 1997; Kenyon, 1990; Bo et al., 2018), the 1D models below assume a linear thermal driving term (e.g. Schumann, 1929; Kuznetsov, 1994; Spiga and Spiga, 1981). In the following section, the basic results of the 1D model are presented, followed by a discussion of their limitations and implications. Although idealized, the models provide a first-order assessment of the temporal and spatial scales over which thermal disequilibrium can play a role in warming and therefore weakening the lowermost CLM. The estimated rates and spatial scales of disequilibrium heating from the models are compared to geologic observations within the western US, specifically geochemical and petrologic evidence for the upward migration of the LAB during Cenozoic melt-rock interaction (Plank and Forsyth, 2016; Farmer et al., 2020).

\section{Model of disequilibrium heat transport}

70 The starting point for the models explored here is a simple, 1-D theory of heat exchange in packed porous beds by Schumann (1929), where fluid moves within the pores of a matrix of solid grains and the only variability in temperature (and temperature contrast between solid and fluid) is in the transport direction. In Schumann (1929), the thermal evolution of the system is governed mainly by heat exchange across the solid-fluid interfacial surface. This heat exchange is assumed to dominate over thermal dispersion and axial conductive heat fluxes both within the moving fluid and in the surrounding regions. Additionally, heat exchange is assumed to be linearly proportional to the local temperature difference between solid and fluid. These arguments lead to coupled equations for the temperature of the solid matrix, $T_{s}$, and within the fluid, $T_{f}$ :

$$
\frac{\partial T_{f}}{\partial t}+v \frac{\partial T_{f}}{\partial x}=-\frac{k}{\phi c_{f}}\left(T_{f}-T_{s}\right)=-k_{f}\left(T_{f}-T_{s}\right)
$$

$$
\frac{\partial T_{s}}{\partial t}=\frac{k}{(1-\phi) c_{s}}\left(T_{f}-T_{s}\right)=k_{s}\left(T_{f}-T_{s}\right)
$$

where $v$ is the transport velocity, $\phi$ is a fluid volume fraction, and $c_{f}$ and $c_{s}$ are the heat capacities per unit volume at constant pressure, so $c_{f}=c_{p f l u i d} \rho_{f}$ and $c_{s}=c_{p s o l i d} \rho_{s}$. Note that the geometry of the solid-fluid interface is not treated in detail, but is idealized in the volume fraction, $\phi$ and in the fluid-solid heat transfer coefficient, $k$. The Schumann (1929) model has been investigated in numerous previous studies and analytic solutions for Eqns 1 and 2 have been derived for a number of limiting cases, particularly for large $k$ (Spiga and Spiga, 1981; Kuznetsov, 1994, 1995a, b, 1996).

In this study, I present a re-interpretation of the equations above and of the heat transfer coefficient. Instead of considering fluid moving in pores between solid grains, the system of equations above may be used to describe thermal disequilibrium between material within high-porosity channels and outside channels. In other words, here "fluid" is interpreted to be inchannel material and "solid" is material outside channels (for simplicity, however, I retain the subscripts $f$ and $s$ as above). 
The velocity $v=v_{\text {channel }}$ is therefore an average relative velocity across channel walls. This "coarse-graining" of the model must also be accompanied by an appropriate reinterpretation of the heat transfer coefficient, $k$, but solutions of Eqns 1 and 2 (particularly analytic solutions in limiting cases) above may be exploited. This reinterpretation is possible because in the framework above the geometry of the interfacial surface is not explicitly specified.

The reinterpreted model is applied to a semi-infinite domain where fluid transport occurs in high-porosity channels aligned in one direction (Figure 1). The high-porosity channels are assumed to occupy a constant volume fraction, $\phi$, within which

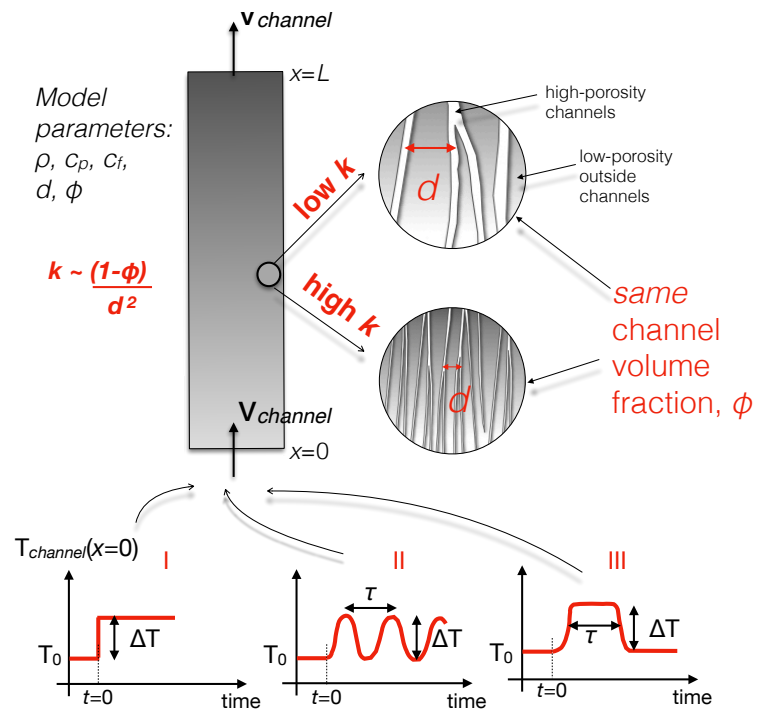

Figure 1. Cartoon of 1D model with parameters such as: specific heat capacities $\left(c_{p}\right)$ and densities $(\rho)$, in-channel velocity $v_{c h a n n e l}$, channel volume fraction, $\phi$, and the heat transfer coefficient $k$ (Table A1 for values). For a given channel volume fraction, $\phi$, the heat transfer coefficient $k$ is a function of the geometry of the channels and scales as $d^{-2}$, where $d$ is the channel spacing (see Appendix C); large $k$ corresponds to large channel wall area per unit volume (e.g., small $d$ ) and vice versa. The input in-channel temperature vs. time functions considered in this study are shown in the three graphs below: (I) Step function; (II) Sinusoid; (III) Finite-duration pulse.

material moves with a constant (average) velocity $v_{\text {channel }}$ relative to the surrounding stationary material outside the channel (volume fraction $1-\phi$ ). The model domain may be thought of as co-moving with the reference frame of material outside the channels. Because of the assumptions built-in to the 1D Schumann (1929) approach, the results below are applicable to physical situations where: transport is dominantly in the along-channel direction; heat exchange across channel walls dominates over conduction within channels and within walls; and any motion of material outside channels is steady.

The model assumes that the channel geometry is unchanging within the domain. The detailed geometry of the channel walls (the relevant interfacial surface here) is not specified but is parametrized by the heat transfer coefficient, $k$ (Figure 1). Therefore, $k$ is a proxy for the geometry of the channel wall interface, namely the wall area per unit volume, controlled by the spatial scale of channelization, $d$ (Appendix C). As illustrated in Figure 1, a large value of $k$ may represent efficient heat exchange as in the case of many channels separated by a small distance. Conversely, a low value of $k$ would represent inefficient exchange, as in the case of a larger characteristic separation between the channels. 
https://doi.org/10.5194/se-2022-13

Preprint. Discussion started: 17 February 2022

(c) Author(s) 2022. CC BY 4.0 License.

(c) (i)

The two independent factors on the right hand sides of Eqns 1 and 2 specify the timescales of heat exchange within channels,

$t_{f}=1 / k_{f}=\phi c_{f} / k$, and outside channels, $t_{s}=1 / k_{s}=(1-\phi) c_{s} / k$. Instead of solid and fluid heat capacities per unit volume (heat capacitances) as in Schumann (1929), here $c_{f}$ and $c_{s}$ now represent an average heat capacitance within and outside channels, respectively. If the material in-/outside of the channels is characterized by a grain-scale porosity, $\varphi_{\text {in }}$ or $\varphi_{\text {out }}$, then $c_{f}$ and $c_{s}$ may be written as the volume-average of the values for solid grains and melt (Appendix $\mathrm{C}$ ) . A characteristic length scale emerges out of the relative motion across channel walls, $v_{\text {channel }} / k_{f}$. These characteristic length and timescales are used to non-dimensionalize Eqns 1 and 2 (Appendix B) and obtain the results presented below. The behavior of the model is determined by five user-specified quantities: the heat transfer coefficient, $k$, channel volume fraction $\phi$, the heat capacitances, $c_{f}$, and $c_{s}$, and the relative velocity across channel walls, $v_{\text {channel }}$ (see values in Table A1).

\subsection{Heat transfer coefficient}

Before discussing model results, I consider the meaning of the heat transfer coefficient, $k$, and the related constants, $k_{s}=$ $k /\left(c_{s}(1-\phi)\right)$ and $k_{f}=k /\left(c_{f} \phi\right)$ in Eqns 1 and 2. Since $k_{f}$ and $k_{s}$ have dimensions of inverse time, $k$ represents the amount of heat transferred across channel walls per unit time, per unit volume, per unit difference in temperature (in Schumann, 1929, this exchange is across the solid-fluid interface).

The factors that determine $k$ are explored in Appendix C; in summary: for a given channel volume fraction, $\phi, k$ is strongly controlled by the length scale of channelization, parameterized by the channel spacing $d$. Therefore, to decide on a range of $k$ values appropriate to the LAB, I turn to observations of the scale of channelization in exhumed portions of the lower CLM. Structural, petrologic, and geochemical data from the Lherz Massif suggest that melt-rock interaction has driven refertilization of a harzburgite body into lherzolite (LeRoux et al., 2007, 2008). In the field, the lherzolite bodies are separated from each other by distances of several tens of meters and this is also the spatial scale of isotopic disequilibrium between metasomatizing fluids and the harzburgite parent material (LeRoux et al., 2008). With this as a proxy for the spatial separation of fluid-rich channels, I choose a broad range for the relevant spatial scale of channelization, $d=10^{0}$ to $10^{3} \mathrm{~m}(1 \mathrm{~m}$ to $1 \mathrm{~km}$ channel spacing). The corresponding range of the heat transfer coefficient in the models is therefore $k \approx 10^{-5}$ (large $d$ ) to $10^{1}$ (low $d$ ) in $\mathrm{W} \mathrm{m}^{-3} \mathrm{~K}^{-1}$ (Figure A1). In the following, material properties, channel volume fraction, in-channel velocity, and heat transfer coefficient are fixed for each calculation (Table A1). Taking typical parameters $\phi=0.1, d=100 \mathrm{~m}$, and corresponding $k$ values in Figure A1, typical timescales of response are $t_{s}=1 / k_{s} \approx 250 \mathrm{yrs}$ and $t_{f}=1 / k_{f} \approx 26 \mathrm{yrs}$.

\section{Results}

This section presents the primary findings of the 1D disequilibirum heat exchange model based on Eqns 1 and 2 (and their non-dimensional form in Appendix B). Three scenarios for influx of hotter-than-ambient melt/fluid were considered, in order of increasing complexity (Figure 1): (I) a step-function increase in temperature of the in-channel material; (II) a sinusodal temperature perturbation; and (III) a finite-duration, constant amplitude thermal pulse. The first two scenarios, the step-function 
https://doi.org/10.5194/se-2022-13

Preprint. Discussion started: 17 February 2022

(c) Author(s) 2022. CC BY 4.0 License.

(c) (i)

and sinusoidal perturbations, are discussed in Appendices D and E, respectively, but the key results are summarized here, followed by a discussion of scenario (III), the finite-amplitude pulse.

\subsection{Step- and sine-function thermal perturbations}

As material with a perturbed (higher, in these models) temperature enters the channels, a transient thermal response occurs as the material inside and outside channels begin to equilibrate. As material outside the channels warms, its temperature lags behind that of the channels creating a region of disequilibrium heat exchange that migrates inward into the domain (Figure A2) at a rate less than the in-channel velocity (Appendices D and E). Kuznetsov (1994) derives an analytic expression for the migration rate in the limit that the degree of disequilibrium is small, and the numerical models here extend this.

A key result of the models is that the rate at which the zone of disequilibirum heating migrates (for the step function) or widens (for the sinusoid) into the domain is independent of the type of thermal perturbation and of the heat transfer coefficient, $k$ (Figures A3 and A4). Instead, the location(s) of maximum disequilibrium (maximum $T_{f}-T_{s}$, and therefore the greatest heat exchange) progresses inward into the domain at a rate given by material properties, the channel volume fraction, $\phi$, and the in-channel velocity, $v_{\text {channel }}$, only (Figure A2d),

$V_{\text {diseqm }} \approx v_{\text {channel }}\left(\frac{c_{f}}{c_{s}}\right)\left(\frac{c_{f} \phi}{c_{f} \phi+(1-\phi) c_{s}}\right)$

Although the rate of migration of the disequilibrium front is not a function of the heat transfer coefficient, the characteristic width of this zone and the degree of disequilibrium within it are strong functions of $k$ (Figures A3 and A4).

A second key result that emerges from the results of a step-function or sinusoidal perturbation is that the degree of disequilibrium decreases exponentially as the zone of disequilibrium either migrates inward (step function, Figure A2) or widens (sinusoid, Figure A4). This effect is identical to the exponentially-decaying degree of chemical disequilibrium obtained using a very similar set of equations as 2 and 1 in the analytic solutions of Kenyon (1990), used to benchmark the models here. As a consequence of the inward-decaying degree of disequilibrium between material inside and outside of channels, the disequilibrium heat exchange occurs only within a certain distance, $\delta$, of the inlet $(x=0)$, within a "thermal reworking zone" or TRZ (Figure A4a-c). The analytic solutions in Spiga and Spiga (1981) and Kenyon (1990) agree with the model results: for fixed in-channel velocity $v_{\text {channel }}$, the width of the TRZ, $\delta$, scales as $\delta \sim(\tau / d)^{2}$ (Figure A4d), where $\tau$ is the period of the sinusoidal thermal perturbation.

\subsection{Finite pulse, duration $\tau_{p}$, amplitude $\Delta T$}

Here we consider the fate of a finite-duration thermal pulse, representing episodic infiltration of melts that are hotter than the ambient CLM. This scenario introduces a timescale into the problem, the pulse duration $\tau_{p}$, implemented here as a tanhfunction $(1 / 2)\left(\tanh \left(\frac{\left.\left(t-\tau_{p} / 2\right)\right)}{w}\right)-\tanh \left(\frac{\left(t-3 \tau_{p} / 2\right)}{w}\right)\right)$ with a characteristic growth/decay timescale $w$ that depends upon $\tau_{p}$, e.g., $w=0.1 * \tau_{p}$ in these models. The results for a finite duration pulse, exemplified in Figure 2, are consistent with the characteristic transient behavior already apparent in the sine and step function perturbations above. The thermal perturbation 

amplitude (Figure 2a). Similarly, the degree of disequilibrium, $T_{f}^{\prime}-T_{s}^{\prime}$, migrates into the domain at a rate given by Eqn 3 and decays during transport (Figure 2b).

(a)

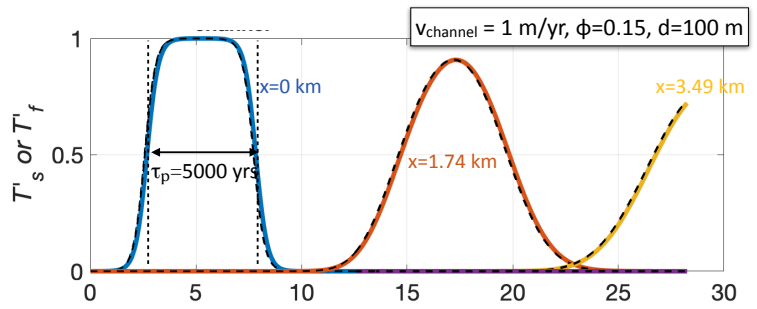

(b)

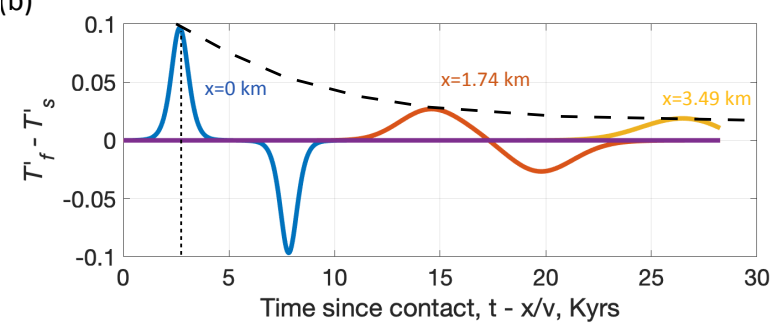

Figure 2. (a) Temperature-time history for a model with for a model with in-channel velocity $v_{\text {channel }}=1 \mathrm{~m} / \mathrm{yr}$, channel volume fraction $\phi=0.15$, and channel spacing $d=100 \mathrm{~m}$, subject to a thermal pulse of duration $\tau_{p}=5 \mathrm{Kyrs}$. Normalized temperature outside channels ( $T_{s}^{\prime}$, solid lines) and within channels ( $T_{f}^{\prime}$, thinner dashed lines) at varying locations within the domain ( $x$, as indicated) are plotted as a function of time since contact with material that entered channels at $x=0, t=0$. Note that $T_{f}^{\prime}(x=0, t)$ is the tanh thermal pertubation function discussed in the text. (b) The degree of disequilibrium, $T_{f}^{\prime}-T_{s}^{\prime}$ for the same $x$ locations as in (a), plotted as a function of time since contact with material that entered channels at $x=0, t=0$. Curved dashed line illustrates an exponentially-decaying envelope that is used to estimate $\delta$, the width of the TRZ (Figure 3).

As we saw with the sinusoidal perturbation, these effects lead to a TRZ that widens over time to a maximum width, $\delta$, that scales with the duration of the thermal pulse $\tau$, channel spacing $d$, and volume fraction $\phi$. For a given channel spacing $d$, which strongly controls the heat transfer coefficient, $k \sim d^{-2}$ (large $d$, small $k$ ), I consider a range of plausible channel volume fractions $\phi=0.01$ to 0.2 , and the corresponding range of $z$ values (Table A1). Figure 3 illustrates how, for fixed $v_{\text {channel }}=1$ $\mathrm{m} / \mathrm{yr}$, parameters $d, \phi$, and $\tau$ lead to variable TRZ widths, $\delta$. Whereas the scaling the scaling exponent $n$ in $\delta \sim(\tau)^{n}$ is exactly 2 for the pure sinusoid (Figure A4d), the finite-duration pulse results point to an $n$ value likely less than 2 (Figure 3). To obtain a TRZ width between 1 to $10 \mathrm{~km}$, we require channel spacings around $d=10$ (with $\phi=0.1$ to 0.2 ) to $d=100 \mathrm{~m}$ (with $\phi \approx 0.01$ ) and thermal pulse durations of 0.1 to $10^{4}$ yrs (Figure 3).

\section{Discussion}

The model scenarios considered above are idealized and therefore limited in their representation of the complexities of deformation and fluid-rock interactions within the CLM. In particular, the effective thermal properties and the geometry of the 


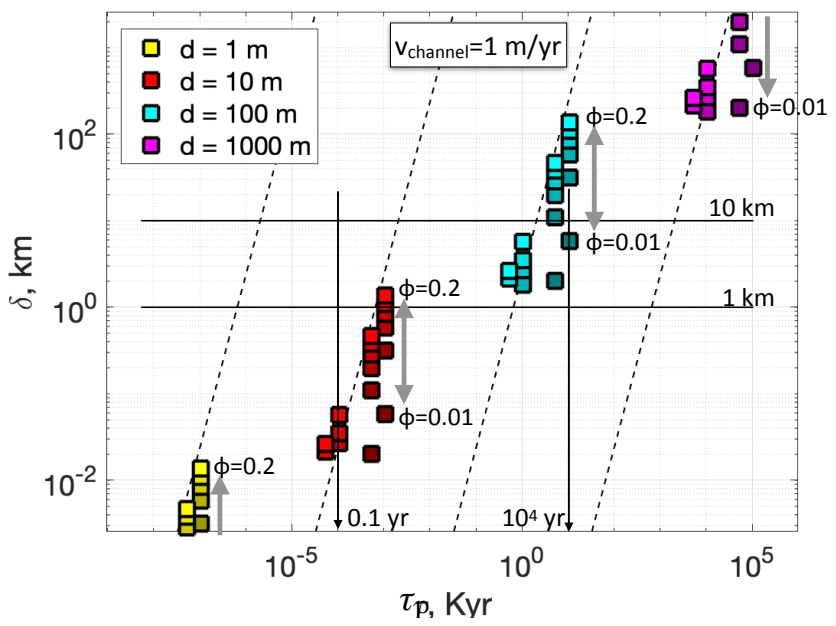

Figure 3. Width of the TRZ, $\delta$, as a function of thermal pulse duration, $\tau_{p}$, for calculations with $v_{\text {channel }}=1 \mathrm{~m} / \mathrm{yr}$ transport velocity and variable channel spacing, $d$. Numerically derived values of $\delta$ are obtained by fitting an exponential decay to the maximum degree of disequilibrium $\max \left(T_{f}^{\prime}-T_{s}^{\prime}\right)$, e.g, Figure $2 \mathrm{~b}$. For given $d$ and $\tau_{p}, \delta$ is a function of channel volume fraction $\phi=0.01$ to 0.2 (Table A1); the color saturation of the symbols corresponds to $\phi$ : darkest $=\phi_{\min }=0.01$ and lightest $=\phi_{\min }=0.2$. Dashed lines (slope 2 ) are the expected analytic scaling in Eqn E1 and horizontal lines indicate $\delta=1$ or $10 \mathrm{~km}$.

fluid-/melt-rich channels are abstracted into a single number, the heat transfer coefficient, $k$, strongly controlled by the channel spacing, $d$. Sinuosity and other aspects of the geometry of channelization are abstracted and the details of processes at and below the scale of an average channel spacing, $d$, are ignored. Instead, the focus here is on the effective behavior at mesoscopic spatial scales $\gg d$. Even at these scales, this formulation ignores spatial variations in transport, including variability in the channel volume fraction $\phi$, in-channel velocity $v_{\text {channel }}$, and effective heat transfer coefficient $k$. Time-dependent variability in transport is also ignored, e.g., feedbacks due to possible phase changes during disequilibrium heating/cooling which would affect the geometry of the channels (Keller and Suckale, 2019). Finally, this 1D model ignores the 3D nature of relative motion across channel walls even on the mesoscale $(\gg d)$.

Given these limitations, the models above are a way to frame first-order questions and develop arguments related to the consequences of disequilibrium heating, particularly when the behavior is dominated by downstream effects in the direction of transport. Taking the model domain to be analogous to the lowermost lithosphere, where melt or fluid transport may be channelized (Figure 4), $x<0$ corresponds to a melt-rich sub-lithospheric region (e.g. a decompaction layer, Holtzman and Kendall, 2010), whereas the domain $x>0$ represents an initially sub-solidus lowermost CLM, and $x=0$ is the initial LAB (Figure 4). Melt-infiltration into the lithosphere may be episodic, controlled by timescales associated with transport from the melt-generation zone to the LAB (e.g., Scott and Stevenson, 1984; Wiggins and Spiegelman, 1995), processes of fracturing and crystallization in a dike boundary layer (e.g., Havlin et al., 2013) and melt supply from a deeper region of melt production (e.g., Lamb et al., 2017).

Three key results emerge from the models above: (1) disequilibrium heating, estimated using the heat transfer coefficient, may be a significant portion of the heat budget at the LAB and the lowermost CLM, (2) there is a material-dependent velocity 
(a)

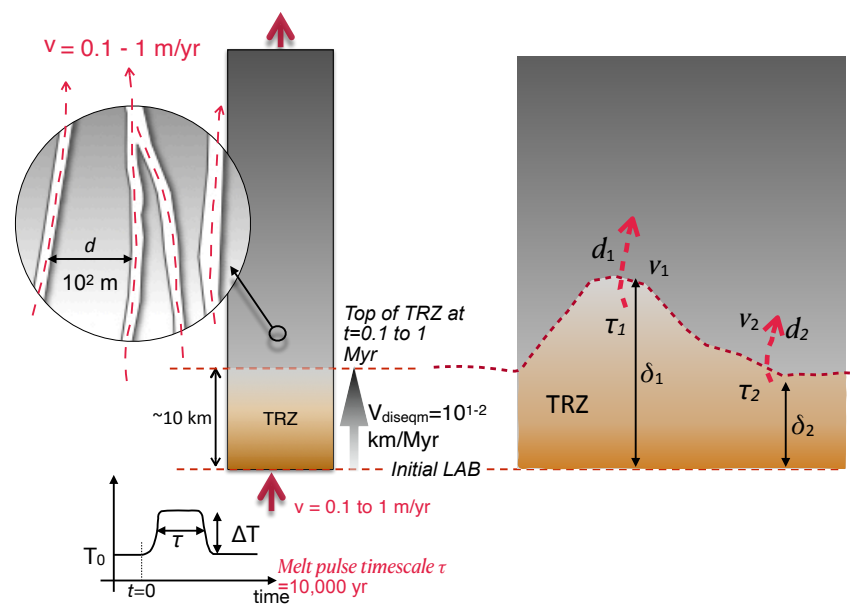

Figure 4. Implications for a thermal re-working zone (TRZ) that forms a modified layer at the lowermost CLM as a result of disequilibrium heating. (a) Cartoon illustrating a specific set of parameters that lead to TRZ growth to a steady-state width of $\delta \sim 10 \mathrm{~km}$, after 0.1 to $1 \mathrm{Myr}$ : duration of melt-infiltration $\tau=10^{4} \mathrm{yrs}$, channel spacing $d=100 \mathrm{~m}$, and in-channel material velocity $v_{\text {channel }}=0.1$ to $1 \mathrm{~m} / \mathrm{yr}$. The TRZ is characterized by upward-decreasing degree of disequilibrium (indicated by the color). Before reaching its final width, the TRZ transiently grows at a relatively fast rate, $V_{\text {diseqm }}>10 \mathrm{~km} / \mathrm{Myr}$. (b) Cartoon illustrating an interpretation of spatially variable TRZ width, $\delta(x)$, as due to lateral juxtaposition of multiple regions of dominantly vertical (1D) transport, but with spatially variable $d, v$, and $\tau$. In this case, $\delta_{1}>\delta_{2}$, which could be due to $d_{1}<d_{2}$, or $v_{1}>v_{2}$, or $\tau_{1}>\tau_{2}$, or some combination of these.

associated with transient disequilibrium heating, and (3) there is a region of spatio-temporally varying disequilibrium heat exchange, a thermal reworking zone (TRZ). Below I discuss each of these within the context of episodic melt-infiltration into the CLM in an intra-plate setting, specifically the Basin and Range province of the western US where deformation and 3D melt transport may be simplified by neglecting plate-boundary effects. In this case, dominantly vertical heat transport within a slowly deforming lithosphere is a reasonable first-order assumption.

i. Disequilibrium heating and the heat budget at the $\mathrm{LAB}$. The relative importance of disequilibrium heating at the $\mathrm{LAB}$ may be established by considering the effective heat transfer coefficient, $k$, and the parameter which most strongly controls it, namely the average spacing of channels, $d$. For the material parameters in Table A1, and channel spacing of $d=1$ to 1000 $\mathrm{m}, k$ is in the range $k \approx 10^{-5}$ to $10^{1} \mathrm{~W} \mathrm{~m}^{-3} \mathrm{~K}^{-1}$ (Appendix C). Physically, $k$ corresponds to across-channel heat transfer per unit time, per unit volume, per unit difference in temperature (Schumann, 1929). Therefore, for a $100 \mathrm{~K}$ excess temperature of the infiltrating melt, disequilibrium heating might contribute around $10^{-3}$ to $10^{3} \mathrm{~W} \mathrm{~m}^{-3}$ to the heat budget at the LAB. This is a conservative estimate, given that the temperature difference between magma and the surrounding material may be larger (e.g., in Lherz the inferred contrast is $>200 \mathrm{~K}$ (Soustelle et al., 2009); and up to $1000 \mathrm{~K}$ in crust; (Lesher and Spera, 2015)). Similarly, plume excess temperatures are estimated to be as large as $250 \mathrm{~K}$ (Wang et al., 2015).

To put this in perspective, we now compare this estimated heat budget to the heat budget due to crystallization of melt in channels. The contribution from freezing of melt may be estimated using scaling arguments made in Havlin et al. (2013). Assuming that melt and rock are in equilibrium, Havlin et al. (2013) estimate that the heat released by a crystallization front 
https://doi.org/10.5194/se-2022-13

Preprint. Discussion started: 17 February 2022

(c) Author(s) 2022. CC BY 4.0 License.

would contribute around $\rho H S_{\text {dike }}$, where $\rho$ is the melt density, $H$ is the latent heat of crystallization, $S_{\text {dike }}$ is a volumetric flow rate out of a decompacting melt-rich $\mathrm{LAB}$ boundary layer due to diking. For a representative dike porosity of $\phi=0.1$ within the dike, Havlin et al. (2013) estimate $S_{\text {dike }} \approx 0.2 \mathrm{~mm}^{3} / \mathrm{s}$. Taking $\rho=3000 \mathrm{~kg} \mathrm{~m}^{3}$, and $H=3 \times 10^{5} \mathrm{~J} / \mathrm{kg}$, the heat source due to the moving crystallization front would be around $10^{2} \mathrm{~W}$ per dike. If we assume that this heating takes place within a volume that is roughly the dike height $\times$ dike spacing $\times$ dike length, we can determine the volumetric power generated due to crystallization. For example, assuming dike heights of about $1 \mathrm{~km}$ and dike spacing large enough for non-interacting dikes (as estimated by Havlin et al. (2013), a porosity of 0.1 would require a dike spacing of $\sim 1 \mathrm{~km}$ ), the heat source due to a crystallizing dike boundary layer would be $<10^{-4} \mathrm{~W} \mathrm{~m}^{-3}$ (per unit length along strike). These arguments corroborate the idea that disequilibrium heating during melt-rock interaction could be a significant portion of the heat budget at the LAB as compared to other expected processes, such as heating due to crystallization of melt in channels.

ii. Progression of a disequilibrium heating zone/front at a rate $V_{\text {diseqm }}$. The disequilibrium heating front is associated with a migration rate $V_{\text {diseqm }}$ that is less than the in-channel material velocity, $v_{\text {channel }}$ (Eqn 3). Therefore, $V_{\text {diseqm }}$ limits the rate at which the lowermost CLM may be modified by thermal disequilibrium during migration of a disequilibrium front (e.g., Figures 2, A4b). Note that $V_{\text {diseqm }}$ (Eqn 3) is independent of temperature contrast between the CLM and infiltrating melt and depends only on the channel volume fraction, in-channel velocity and material properties. Assuming a channel volume fraction of $10 \%$ at the $\mathrm{LAB}$, and material properties in Table A1, $V_{\text {diseqm }}$ would be around $10 \%$ of the in-channel velocity (see Appendix D, Figure A2d). For in-channel velocity in the range of 0.01 to $1 \mathrm{~m} / \mathrm{yr}$, the disequilibrium heating front at the LAB would migrate upward at a rate of $\approx 1$ to $10^{2} \mathrm{~km} / \mathrm{Myr}$. This is comparable to rates of CLM thinning predicted by heating due to the upward motion of a dike boundary layer (1 to $6 \mathrm{~km} / \mathrm{Myr}$ in Havlin et al. (2013)). Interestingly, an upward-moving disequilibrium heating zone with $V_{\text {diseqm }} \approx 1$ to $10^{2} \mathrm{~km} / \mathrm{Myr}$ also brackets the $10-20 \mathrm{~km} / \mathrm{Myr}$ rate of upward migration of the LAB inferred from the pressure and temperature of last equilibration of Cenozoic basalts in the Big Pine volcanic Field in the western US (Plank and Forsyth, 2016). An implication of the models here, therefore, is that disequilibrium heating may produce lithosphere modification at geologically-relevant spatial and temporal scales provided that the material velocity in channels at the LAB is on the order of $10^{-1}$ to $1 \mathrm{~m} / \mathrm{yr}$ (e.g., Figure 4; Rutherford, 2008).

iii. Thermal reworking zone (TRZ). A key result that may be relevant to the evolution of the LAB is that episodic infiltration of melts that are hotter than the surrounding CLM would lead to a finite region of disequilibrium heating within a thermal reworking zone or TRZ. The TRZ would undergo a phase of transient widening (at a rate given by $V_{\text {diseqm }}$ ), reaching a maximum width $\delta$ that should scale as $\delta \sim\left[\phi v_{\text {chan }}(\tau / d)^{n}\right](n \approx 2)$ where $d$ is a characteristic scale of channelization and $\tau$ is a timescale associated with the episodicity of melt-infiltration (Figure 3; also A4d). This scaling gives us a way to conceptualize the modification of the lowermost CLM as a zone that may encompass a variable thickness TRZ, depending on variability in transport velocity and in the timescale of melt-infiltration (Figure 4). Regions where the timescale of episodic melt-infiltration is longer are predicted to have a thicker zone of modification at the LAB (Figure 3). For example, for a channel spacing of $d=10^{2} \mathrm{~m}$, disequilibrium heating by melt pulses that last around $10 \mathrm{Kyrs}$ implies a maximum thickness of roughly $10 \mathrm{~km}$ for the zone of modification (Figure 3; also A4d). In this scenario, the TRZ grows to this maximum width over a timescale governed by $\delta / V_{\text {diseqm }}$; for $V_{\text {diseqm }}=10 \mathrm{~km} / \mathrm{Myr}$, which corresponds to melt velocity of roughly $0.1 \mathrm{~m} / \mathrm{yr}$ (see (ii) above), 
https://doi.org/10.5194/se-2022-13

Preprint. Discussion started: 17 February 2022

(c) Author(s) 2022. CC BY 4.0 License.

\section{(c) (i)}

the $10 \mathrm{~km}$ wide TRZ would be established within about $1 \mathrm{Myr}$ (Figure 4), comparable to rates of CLM modification inferred from observations in Plank and Forsyth (2016).

These scaling arguments lead to the idea that perhaps the TRZ represents a zone of thermal modification at the base of the CLM that may also correspond to (or encompass) a zone of rheologic weakening and/or in-situ melting if the infiltrating fluids are hotter than the ambient material. The dynamic evolution of the LAB during episodic pulses of melt-infiltration is beyond the scope of the simple models above (which assume a stationary, undeforming matrix). However, assuming mantle material obeys a temperature and pressure-dependent viscosity scaling relation such as in Hirth and Kohlstedt (2003) at an LAB depth of about $75 \mathrm{~km}$, where the ambient mantle is cooler than the dry solidus (e.g., $1100^{\circ} \mathrm{C}+3.5^{\circ} \mathrm{C} / \mathrm{km}$; Plank and Forsyth (2016)), we would expect a significant viscosity reduction during heating (e.g., factor $\approx 1 / 62$ for a temperature increase of $100 \mathrm{~K}$ ). This effect is weaker, but still important for a deeper LAB; e.g, at $125 \mathrm{~km}$ depth, the viscosity reduction would be a factor $\approx 1 / 18$ for a temperature increase of $100 \mathrm{~K}$.

Geochemical evidence from Cenozoic basalts from the western US, particularly space-time variations in volcanic rock Ta/Th and $\mathrm{Nd}$ isotopic compositions suggest that the timescale of modification and removal of the lowermost CLM is on the order of $10^{1}$ Myrs (Farmer et al., 2020). These authors argue that the observed transition from low to intermediate to high Ta/Th ratios indicates a change from: arc/subduction-related magmatism, to magmatism associated with in-situ melting of a metasomatized CLM (the "ignimbrite flare-up"), to magmatism due to decompression and upwelling after removal of the lowermost CLM. At a minimum, the observed timescale of the transition in Ta/Th ratios in volcanic rocks (10 $10^{1} \mathrm{Mrs}$ ) in the western US should be comparable to the timescales of degradation of the CLM. If correct, these interpretations and observations are promising and provide an important avenue for exploring the role of thermal and chemical disequilibrium during melt-rock interaction and destabilization of the CLM in an intra-plate setting.

\section{Conclusions}

In summary, I have presented arguments supporting the role of disequilibrium heating in the modification of the base of the CLM during melt-infiltration into and across the LAB. Infiltration of pulses of hotter-than-ambient material into the LAB should establish a thermal reworking zone (TRZ) associated with disequilbrium heat exchange. The spatial and temporal scales associated with the establishment of the TRZ are comparable to those for CLM modification inferred from geochemical and petrologic observations intra-plate settings, e.g., the western US. Disequilibrium heating may contribute more than $10^{-3} \mathrm{~W} / \mathrm{m}^{3}$ to the heat-budget at the LAB and, for transport velocity of 0.1 to $1 \mathrm{~m} / \mathrm{yr}$ in channels that are roughly $10^{2} \mathrm{~m}$ apart, a $10 \mathrm{~km}$ wide TRZ may be established within 1 Myr. Disequilibrium heating during melt-infiltration may therefore be an important process for modifying the CLM. Further work is needed to explore its role in the rheologic weakening that must precede mobilization (and possibly removal) of the lowermost CLM. 
https://doi.org/10.5194/se-2022-13

Preprint. Discussion started: 17 February 2022

(c) Author(s) 2022. CC BY 4.0 License.

(c) (i)

\section{Appendix A: Geologic observations}

This study is inspired by geologic evidence from the Lherz and Ronda peridotite massifs for the role of thermal disequilibrium in the lower continental lithosphere (Bodinier et al., 2008, 1990; LeRoux et al., 2007; Lenoir et al., 2001; Saal et al., 2001; Vauchez and Garrido, 2001; LeRoux et al., 2008, 2007, 2008; Soustelle et al., 2009). Two important conclusions relevant to this work emerge from studies in the Lherz and Ronda peridotite massifs: (1) First, we now know that "lherzolite" (named after its type-section in the Lherz massif), commonly regarded as pristine, fertile sub-continental lithospheric mantle, may be derived from refertilization of a depleted, harzburigitic parent (e.g., LeRoux et al., 2007, 2008); (2) Second, careful microstructural, geochemical and petrologic work has documented the dominant effect of a steep thermal gradient associated with the region of contact and interaction between partial-melt-rich regions and the surrounding lithosphere.

The importance of thermal disequilibrium in the lower lithosphere is most clearly demonstrated by in Ronda (Soustelle et al., 2009). These workers provide a quantitative estimate of a transient thermal gradient $\left(\approx 230^{\circ} \mathrm{C} / \mathrm{km}\right.$, or more than an order of magnitude larger than a typical equilibrium geothermal gradient expected at the LAB). Soustelle et al. (2009) show that thermal disequilibrium heating also drove partial-melting of the lithosphere above/around the melt-rich region. Indeed, the authors recognize this as a transient LAB and coin the term "asthenospherization" for the thermally-controlled disequilibrium processes, including heating. The spatial scale over which this disequilibrium heating is observed in Ronda $(\sim 1 \mathrm{~km})$ guides the mesoscale modeling approach here.

Interpreting the observed region of thermal disequilibrium as part of the TRZ, I explore what timescales of melt-infiltration give rise to TRZ widths on the order of 1-10 km (Figure 3). The horizontal lines in Figure 3 denote the timescales of meltinfiltration that would be required to give rise to a $10^{0}$ to $10^{1} \mathrm{~km}$ region where thermal disequilibrium may be important.

\section{Appendix B: Nondimensional system}

To non-dimensionalize the system of equations 1 and 2 (e.g., Spiga and Spiga, 1981), we define the normalized relative temperature, $T_{f}^{\prime}=\left(T_{f}-T_{0}\right) / \Delta T$ and $T_{s}^{\prime}=\left(T_{s}-T_{0}\right) / \Delta T$, where $T_{0}$ is reference temperature and $\Delta T$ is a temperature perturbation (described below). We also introduce the dimensionless position, $x^{\prime}=x k_{f} / v_{\text {channel }}$, a dimensionless time, $t^{\prime}=k_{s} t$, and the heat capacitance ratio $z=k_{s} / k_{f}=\phi c_{f} /(1-\phi) c_{s}$. The non-dimensional versions of equations 1 and 2 are now (B1) and (B2):

$z \frac{\partial T_{f}^{\prime}}{\partial t^{\prime}}+\frac{\partial T_{f}^{\prime}}{\partial x^{\prime}}=-\left(T_{f}^{\prime}-T_{s}^{\prime}\right)$

$\frac{\partial T^{\prime}{ }_{s}}{\partial t^{\prime}}=\left(T_{f}^{\prime}-T_{s}^{\prime}\right)$ 
(see also Spiga and Spiga (1981)). It is clear that for a given temperature difference, $\left(T^{\prime}{ }_{f}-T^{\prime}{ }_{s}\right)$, the behavior of this system is governed by $z(1 / z$ is a dimensionless velocity). Analytic solutions for this set of equations have been derived for a number of limiting cases, particularly for large $k$ (Spiga and Spiga, 1981; Kuznetsov, 1994, 1995a, b, 1996), and were used to benchmark the numerical calculations in this study.

\section{Appendix C: Heat transfer coefficient, $k$, and relation to channel spacing, $d$}

The factors that determine $k$ can be illustrated by considering that the heat transfer rate across channel walls must depend on the geometry of walls and also on the effective thermal conductivity of the channelized domain. Although the geometry of the channels may be complex, this model considers one aspect of it: the specific wall surface area (wall area per unit volume), $a_{s f}$, which is a function of the length-scale of channelization. In the grain-scale porous flow case considered in Schumann (1929) for example, if the solid matrix is made of spheres with an average particle diameter $d$, then the specific area for a grain is $S_{0}=6 / d$, so $a_{s f}=S_{0}(1-\phi)=6(1-\phi) / d$ (Dullien, 1979). This sets a limit for channels, where we shall assume that the specific surface area is $a_{s f} \sim A(1-\phi) / d$, where $A$ is a number that is between 2 (as for a single cylindrical channel with small volume fraction $\phi$ ) and 6 (Dixon and Cresswell, 1979). Whereas the specific wall area is a geometric factor, the effective conductivity of the medium depends on the Nusselt number, $N u$. Theoretical arguments in Dixon and Cresswell (1979) show that the effective thermal conductivity may be written in terms of the individual in-channel and out-of-channel thermal conductivities $\lambda_{f}$ and $\lambda_{s}$ (basically taking the channels and non-channel regions in parallel):

$\frac{1}{C_{e f f}}=\left[\frac{1}{N u \lambda_{f}}-\frac{1}{\beta \lambda_{s}}\right]$

where $\beta=10$ for spherical matrix grains, 8 for cylinders, and 6 for slabs (Dixon and Cresswell, 1979). Therefore, the range of $\beta=6$ to 10 represents the highly-channelized vs porous flow end-member geometries. For slow flows (Reynolds number Re «100), Handley and Heggs (1968) argue that $N u$ ranges from 0.1 to 12.4 (Dixon and Cresswell, 1979) (Table A1). The relevant quantity that determines $k$ is an effective "conductance" $C_{e f f} / d$, so that $k=C_{e f f} a_{s f} / d$,

$k=\left[\frac{1}{N u \lambda_{f}}-\frac{1}{\beta \lambda_{s}}\right]^{-1} \frac{A(1-\phi)}{d^{2}}$

a product of a material-dependent quantity and a geometry-dependent quantity.

Turning now to physical properties relevant to the transport of melts through the lithosphere, the channelized domain may be thought of as consisting of a mixture of melt+grains throughout, but with variable grain-scale porosity $\varphi$. Specifically, the fluid-rich channels would have a higher $\varphi_{f}$ than the surroundings $\varphi_{s}$. The thermal conductivity inside and outside the channels would then be a volume average in each, e.g., inside channels, $\lambda_{f}=\varphi_{f} \lambda_{\text {melt }}+\left(1-\varphi_{f}\right) \lambda_{\text {grain }}$, where $\lambda_{\text {melt }}$ and $\lambda_{\text {grain }}$ are the values for, say basaltic melt and peridotitic grains. Similarly, outside channels the volume average would be $\lambda_{s}=\varphi_{s} \lambda_{\text {melt }}+\left(1-\varphi_{s}\right) \lambda_{\text {grain }}$. Here I do not specify reasonable ranges of $\varphi_{\text {in }}$ and $\varphi_{\text {out }}$, but rather I focus on determining 
https://doi.org/10.5194/se-2022-13

Preprint. Discussion started: 17 February 2022

(c) Author(s) 2022. CC BY 4.0 License.

an upper limit to the role of thermal disequilibrium across channel walls. Therefore, to explore the end-member case, I take

$\varphi_{f}=1$ and $\varphi_{s}=0$, so that $\lambda_{f}=\lambda_{\text {melt }}$ and $\lambda_{s}=\lambda_{\text {grain }}$. Using a reasonable conductivity for basaltic magma of $\lambda_{m e l t}=1 \mathrm{~W}$ $\mathrm{m}^{-1} \mathrm{~K}^{-1}$ (Lesher and Spera, 2015), $\lambda_{\text {grain }}=2.5 \mathrm{~W} \mathrm{~m}^{-1} \mathrm{~K}^{-1}$ ) for the solid grains, and taking $N u=0.1$ to $12.4, \beta=6,8$, or 10 , and $A=6$, we find that the effective conductivity $C_{e f f}, a_{s f}$ and $k$ are within the ranges shown in Figure A1. (Note that choosing $A \approx 2$ would change $k$ by less than an order of magnitude.) Specifically, Eqn (C2) shows that $k \sim d^{-2}$ and strongly decreases with increasing spatial scale of channels; Figure A1c.

\section{Appendix D: Response to a step-function}

The domain is initially at steady-state in equilibrium at temperature $T_{0}=T_{s}=T_{f}$ and at $t=0$ the temperature of the fluid entering at the inflow, $x=0$, is perturbed so that, $T_{f}(x=0, t>0)=T_{0}+\Delta T$ (introducing $\Delta T$ as a temperature scale into the problem). This disturbs the initial steady state and starting at $t=0^{+}$material at the inflow is no longer in thermal equilibrium with material in the domain. As material with a perturbed temperature enters channels at $x=0$, the surroundings heat up while the fluid-rich channels cool (for positive perturbation $\Delta T$ ). The perturbation "front", the farthest extent of channel material with perturbed temperature, is at $x_{\text {front }}=v t$ (or $x_{\text {front }}^{\prime}=t^{\prime} / z$; where the dimensionless velocity inside channels is $1 / z$; see Appendix B).

Non-dimensional equations (B1) and (B2) in Appendix B may be solved for the thermal evolution subject to the initial and boundary condition: $T^{\prime}{ }_{s}=T_{f}^{\prime}=0$ initially and $T_{f}^{\prime}(x=0, t \geq 0)=1$. The behavior of the nondimensional system is controlled by $z$, the dimensionless in-channel velocity, which is a function of both material properties $c_{s}$ and $c_{f}$ and the channel volume fraction, $\phi$. To be consistent with the end-member case discussed in Appendix C, where in-channel grain-scale porosity is taken to be 1 and the out-of-channel is 0 , I use heat capacitances for basaltic melt and peridotitic grains (Table A1). Since the material properties $c_{s}$ and $c_{f}$ are held constant, there is a unique mapping between $z$ and $\phi$, the channel volume fraction (we use $\phi=0.01$ to 0.20 , corresponding to values of $z=0.0096$ to 0.2376 ; Table A1).

As we might expect, the behavior of the nondimensional system (Eqns B1 and B2) is governed by $z$, the heat capacitance ratio. The response to a step-function is essentially a transient disequilibrium front, traveling inward at $V_{\text {diseqm }}$, behind which the solid and fluid equilibrate at the new inlet temperature. In response to a step-function increase in the inlet temperature, temperature profiles within the domain exhibit a transition or disequilibrium zone, lagging behind the fluid front (Figure A2). Ahead of this disequilibrium zone, the channels are in equilibrium with the surroundings at the initial ambient temperature, $T^{\prime}{ }_{s}=T_{f}^{\prime}=0$. Behind this zone, the channels are in equilibrium with the surroundings at the inlet temperature, $T^{\prime}{ }_{s}=T_{f}^{\prime}=1$.

Following an initial lag time (when the maximum disequilibrium is at $x^{\prime}=0$ ), the disequilibrium zone migrates inward migration at a steady speed $V_{\text {diseqm }}$, a fixed fraction of the in-channel velocity, $v_{\text {channel }}$ (Figure A2c and A2d). The ratio of the migration rate of the disequilibrium zone to $v_{\text {channel }}$ is controlled by the heat capacity ratio, $z$, and therefore by the channel volume fraction, $\phi$ (Figure A2). In the near-equilibrium limit, $\left(T_{f}^{\prime}-T_{s}^{\prime} \approx 0\right)$, Kuznetsov (1994) shows that the shape of the temperature difference function (Figure A2b) approaches a Gaussian with width that depends on $\sqrt{t^{\prime}}$ and the zone of disequilibrium migrates at speed $v_{\text {channel }} c_{f} /\left(\phi c_{f}+(1-\phi) c_{s}\right)$. Our models show that, when there is significant disequilibrium, 
https://doi.org/10.5194/se-2022-13

Preprint. Discussion started: 17 February 2022

(c) Author(s) 2022. CC BY 4.0 License.

\section{(c) (i)}

the zone of disequilibrium migrates with a rate given by Eqn 3 (Figure A2d), which does not depend on $k$, the heat transfer coefficient.

Although $V_{\text {diseqm }}$ is independent of $k$, the degree of disequilibirum is not. We illustrate the dependence on $k$ for the specific case where the in-channel velocity $v_{\text {channel }}=1 \mathrm{~m} / \mathrm{yr}$, and consider channel spacings, $d=50$ to $150 \mathrm{~m}$, which correspond to $k=5 \times 10^{-3}$ and $5 \times 10^{-4} \mathrm{~W} \mathrm{~m}^{-3} \mathrm{~K}^{-1}$, respectively (Figure A3).

The migration of the disequilibrium front may be thought of as the motion of the locus of maximum heating, which moves at speed $V_{\text {diseqm }} \approx v_{\text {channel }} / 10$, for $\phi=0.1$ in Figure A3. The degree of disequilibrium within the migrating disequilibrium zone, $D$, decays as $1 / \sqrt{t}$ (e.g., Kuznetsov, 1994) and is controlled by the heat transfer coefficient, $k . D$ scales as $1 / \sqrt{k}$ and therefore is a linear function of $d$, the channel spacing (Figure A3b). This transient is apparent in temperature-time paths (Figure $\mathrm{A} 3 \mathrm{c}$ and $\mathrm{A} 3 \mathrm{~d}$ ), where the approach to steady-state occurs on a timescale governed by $\phi v_{\text {channel }} / k$.

\section{Appendix E: Response to a sinusoidal thermal perturbation}

Here we consider a scenario where the fluid entering the domain is hotter than the ambient initial temperature, but the thermal contrast varies sinusoidally. Although this is an idealized condition, it may be interpreted to represent periodic pulses of high temperature material entering into fluid- or melt-rich channels. Since any continuous time-varying thermal history at the inflow may be represented as a sum of sinusoids, this scenario also allows us to build intuition regarding the inherent length and timescales of equilibration within the medium and how these might interact with the periodic thermal histories. Sinusoidal thermal pulses introduce a new timescale into the problem, the period $\tau$, and the relevant timescale to compare to is $1 / k_{s}$ is the longest response timescale in the domain, associated with the thermal response of the material outside channels. For the material parameters in Table A1, and channel spacing of $d=10$ to $100 \mathrm{~m}$, the characteristic response timescale $1 / k_{s} \approx 1$ to $100 \mathrm{yr}$, which is short compared to the timescales of geologic events.

Thermal pulses with periods that are long compared to $1 / k_{s}$ penetrate farther into the domain than short period oscillations (Figure A4). The non-dimensional period, $\tau k_{s}=\tau k /(1-\phi) c_{s}$, controls the length scale, $\delta$, over which thermal oscillations penetrate into the domain. Therefore, periodic thermal perturbations that might represent melt infiltration pulses lasting $10^{3}$ to $10^{6}$ yrs will be characterized by a region of spatially varying temperatures: a thermal re-working zone (TRZ) (blue lines in Figure A4a \& b). The wavelength of these temperature oscillations is set by the period $\tau, \lambda=v_{\text {channel }} \tau$. The penetration distance of the oscillations, $\delta$, is the maximum width of the TRZ. At short times, when $t \ll \delta / V_{\text {diseqm }}$, there is one zone of disequilibrium (the TRZ, bounded by the disequilibrium front). At longer times, the TRZ widens to a maximum width, $\delta$, at time $\delta / V_{\text {diseqm }}$. When $t \gg \delta / V_{\text {diseqm }} t$, there are two zones of disequilibrium: a stationary one bounded by the inlet with width $\delta$ (the TRZ), and the migrating zone discussed above that moves at $V_{\text {diseqm }}$ (Eqn 3; red lines in Figure A4a $\&$ b). The oscillatory nature of temperatures inside the TRZ is illustrated in temperature vs. time paths within the domain at varying distances from the inlet (Figure A4c). The amplitude of the temperature oscillations decay with distance, but at each location in the TRZ the amplitude is constant, once oscillations are established (Figure A4c). As we might expect, the maximum width of the TRZ, $\delta$, is set both by the non-dimensional oscillation period, $\tau / t_{s}$ and by the heat transfer coefficient (see also Spiga 
https://doi.org/10.5194/se-2022-13

Preprint. Discussion started: 17 February 2022

(C) Author(s) 2022. CC BY 4.0 License.

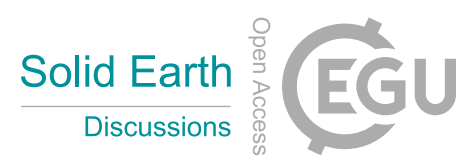

400 and Spiga, 1981; Kenyon, 1990),

$\delta=\left(\frac{c_{f} \phi v_{\text {channel }}}{k}\right)\left(\frac{\left(\tau / t_{s}\right)^{2}}{4 \pi^{2}}\right)$

noting that $k \sim d^{-2}$ (Appendix C), and $t_{s}=1 / k_{s}=c_{s}(1-\phi) / k$, the expression above suggests that, for fixed $v_{\text {channel }}, \delta \sim$ $(\tau / d)^{2}$ as confirmed by the numerical results (Figure A4d). 
https://doi.org/10.5194/se-2022-13

Preprint. Discussion started: 17 February 2022

(c) Author(s) 2022. CC BY 4.0 License.

(a)

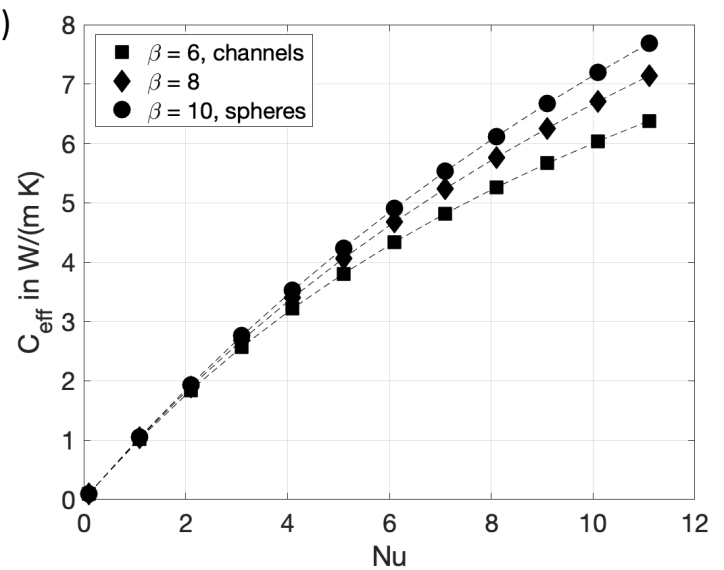

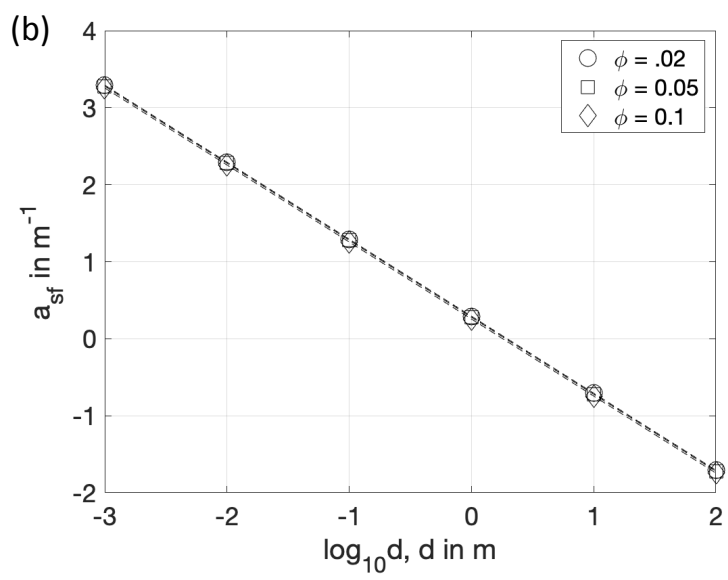

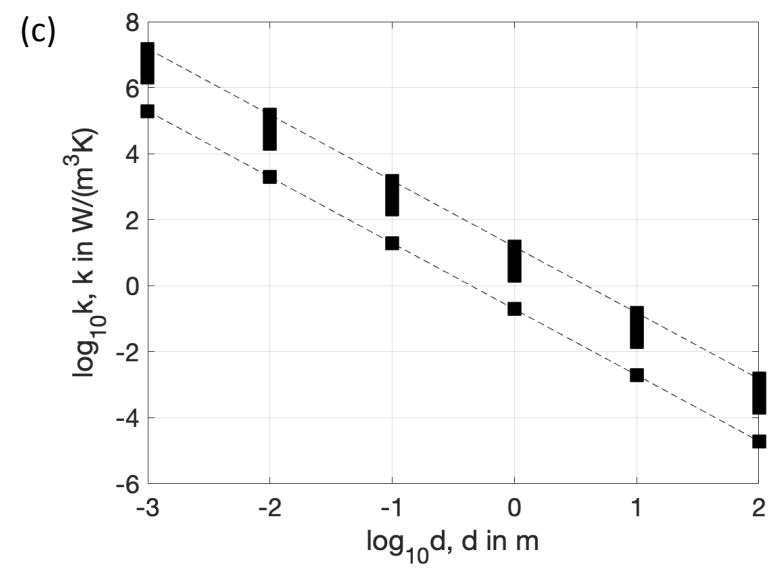

Figure A1. (a) Effective thermal conductivity, $C_{e f f}$ in Eqn C1, as a function of Nusselt number, (b) geometric factor, $a_{s f}$, as a function of channelization scale, $d$, and (c) heat transfer coefficient, $k$, as a function of channelization scale $d$. For a fixed $d$, the dashed lines in (c) delineate the variation in $k$ for the range of $\beta$ values in (a) and $\phi$ values in (b), illustrating that $k$ is mainly controlled by $d$, rather than the other parameters. 

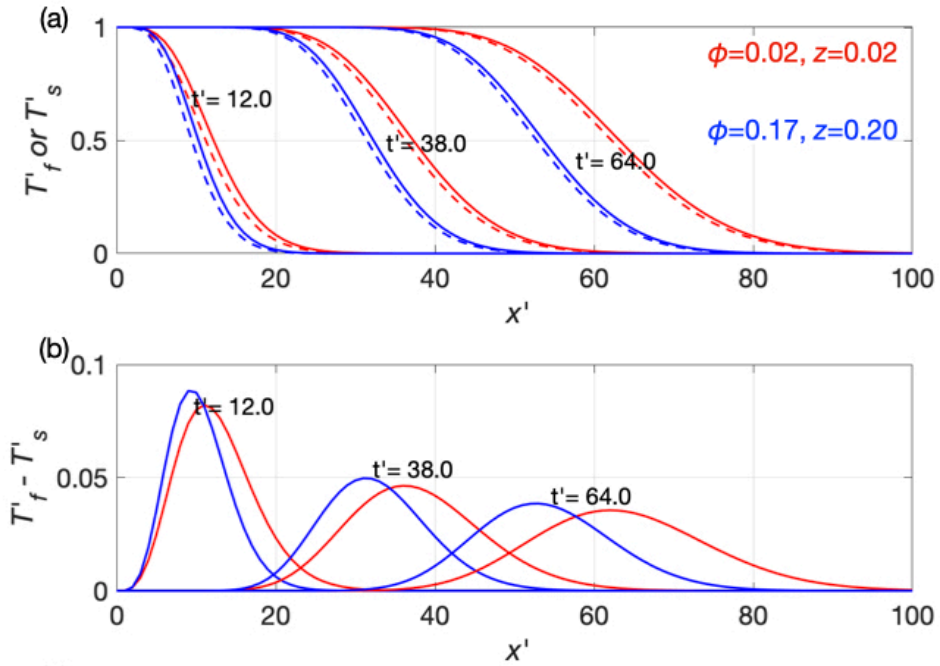

(c)

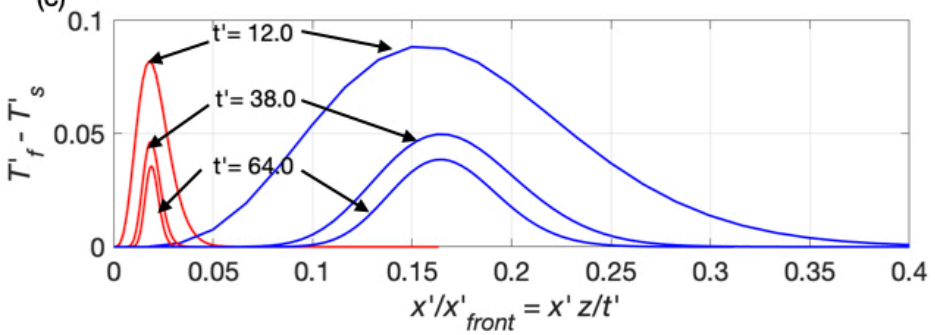

(d)

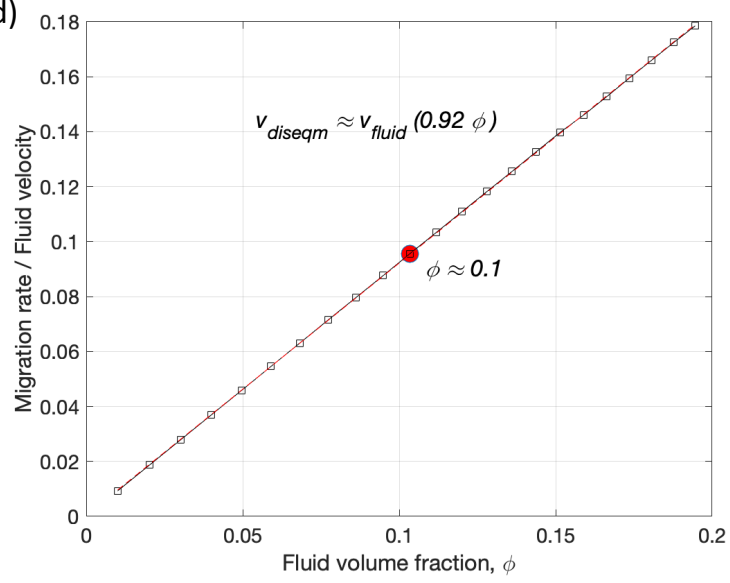

Figure A2. (a) Normalized temperature as a within channels (solid lines) and surroundings (dashed lines) at different values of the dimensionless time, $t^{\prime}$, since a step function perturbation, as indicated. The colors represent two different channel volume fractions, $\phi$, and therefore different $z$. (b) Normalized temperature difference across channel walls as a function of dimensionless position, shown for the cases considered in (a). (c) The same profiles as in (b), but now plotted as a function of position normalized by the perturbation front location, $x_{\text {front }}^{\prime}=t^{\prime} / z$; stationarity of the disequilibrium zone in this plot indicates that the disequilibrium zone migrates at a constant, z-dependent fraction of the in-channel velocity. (d) Normalized migration rate of the zone of disequilibrium as a function of channel volume fraction, $\phi$. Red dot is for $\phi \approx 0.1$, corresponding to models shown in Figure A3 and Figure 2 in text. 


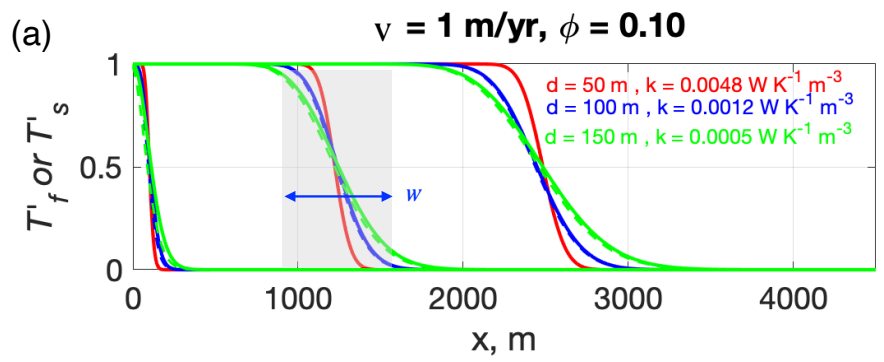

(b)
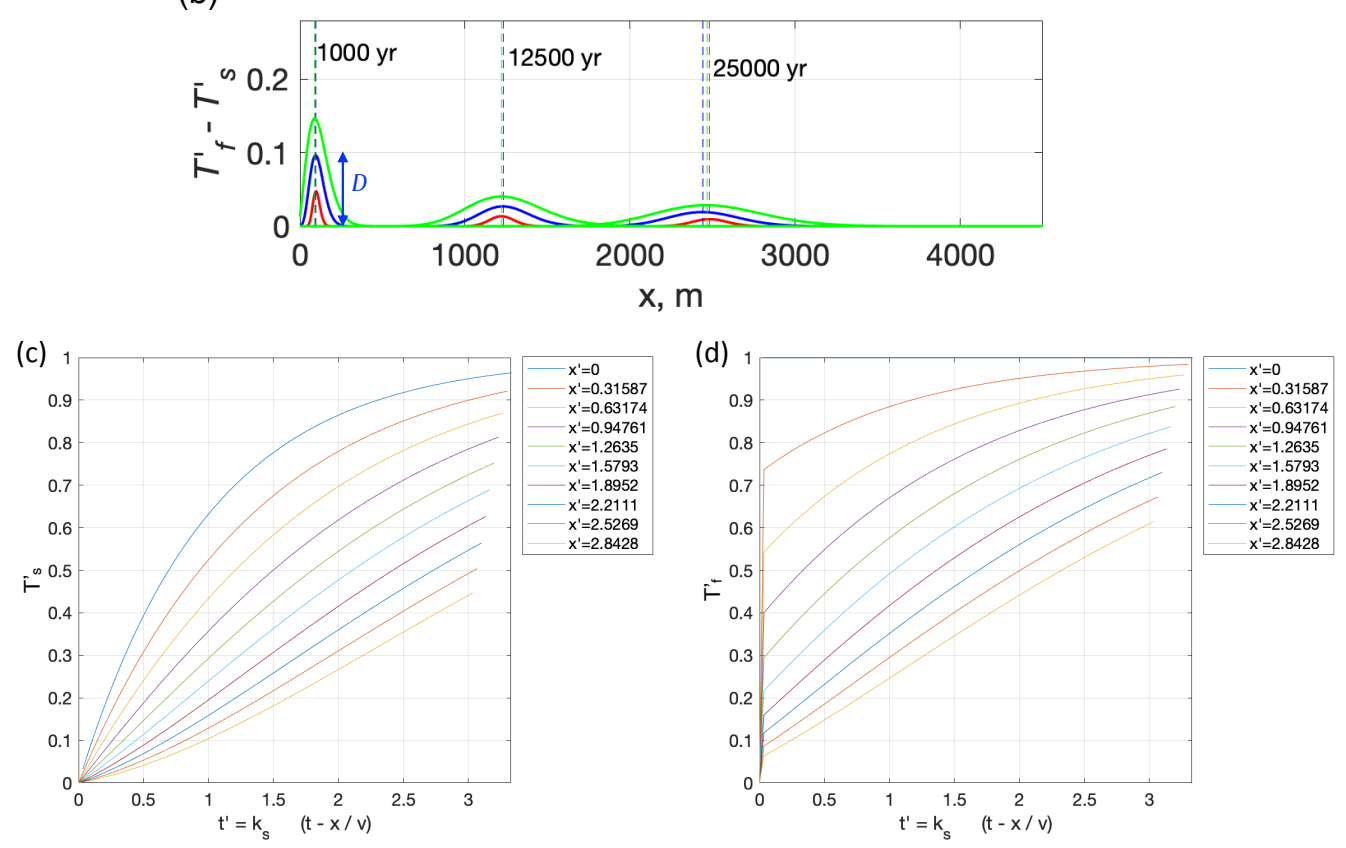

Figure A3. (a) Normalized temperature profiles, $T_{s}^{\prime}$ (dashed) and $T_{f}^{\prime}$ (solid) for in-channel velocity $v_{\text {channel }}=1 \mathrm{~m} / \mathrm{yr}$, at times $t=1$, 12.5 , and $25 \mathrm{Kyr}$. The temperature profiles transition between the incoming channel material temperature (=1, left) and the initial ambient temperature $(=0$, right), for two cases with different channel spacing, $d$, and heat transfer coefficient, $k$, as indicated. The transition region (e.g., highlighted in gray at $t=12.5 \mathrm{Kyr}$ ), has width, $w$, that is larger for smaller $k$ (large $d$ ) and increases over time. (b) The degree of disequilibrium is characterized by the maximum difference across channel walls, $D$. $D$ is greater for smaller $k$ and decreases as a function of time. (c) $T_{s}^{\prime}$ and (d) $T_{f}^{\prime}$ as a function of dimensionless time since first contact with the perturbation front. 
(a)

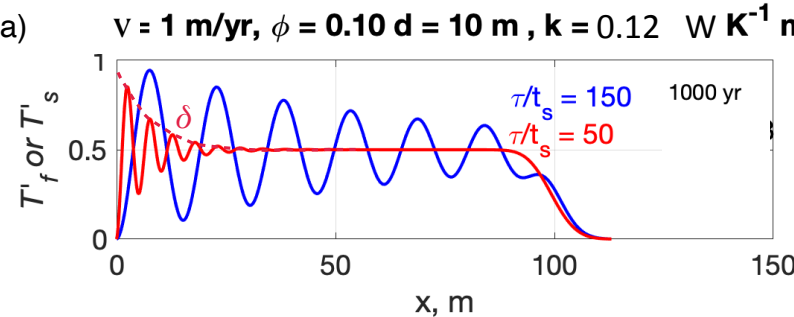

(b)

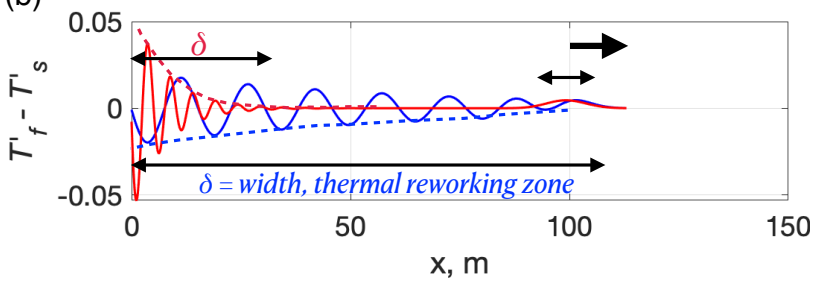

(c)

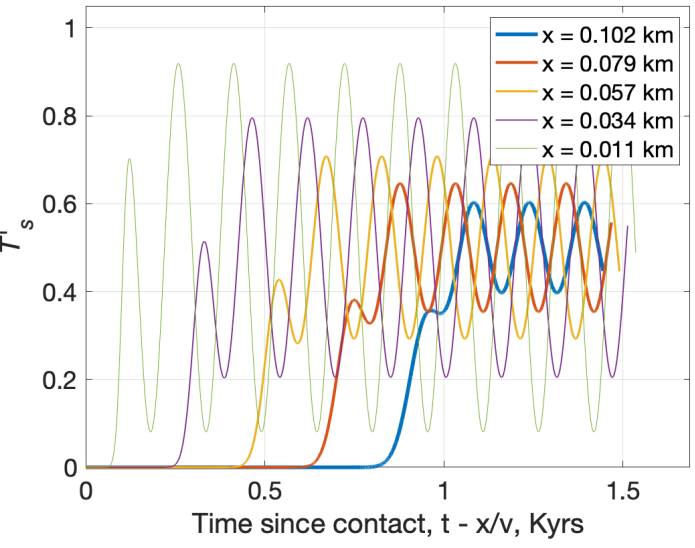

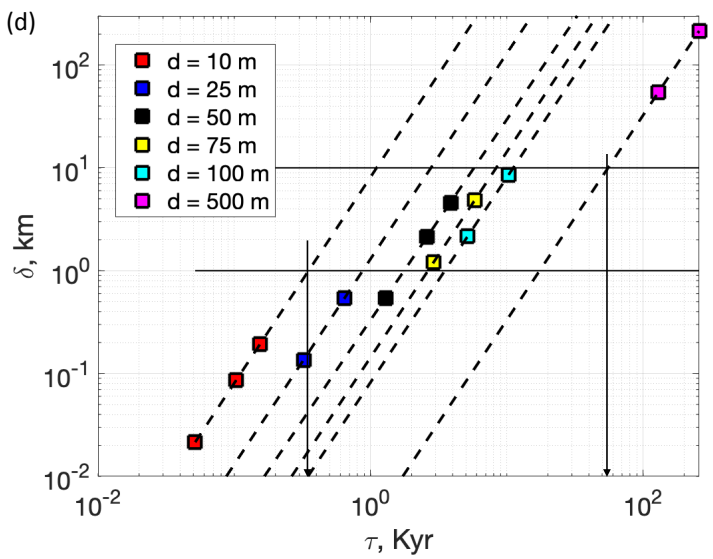

Figure A4. (a) Normalized temperature profiles at time $t=1 \mathrm{Kyr}$, in-channel $T_{f}^{\prime}$ (solid lines), and out-of-channel $T_{s}^{\prime}$ (dashes), for a calculation with in-channel velocity $v_{\text {channel }}=1 \mathrm{~m} / \mathrm{yr}$, channel volume fraction $\phi=0.1$, channel spacing $d=10 \mathrm{~m}$ and heat transfer coefficient $k$ as indicated. For the chosen parameters, the response timescale is $1 / k_{s}=t_{s}=1$ yr. Results are shown for two different thermal pulses in the incoming material with (normalized) oscillation periods: $\tau k_{s}=50$ (red), 150 (blue). The thermal reworking zone (TRZ) has spatial oscillations in $T_{f}^{\prime}$ and $T_{s}^{\prime}$, with amplitudes that decrease over a decay scale $\delta$, the width of the TRZ: $\delta$ is larger for longer period (blue) and shorter for shorter period (red). (b) The degree of disequilibrium $\left(T_{f}^{\prime}-T_{s}^{\prime}\right)$ is also oscillatory in the TRZ, with decaying amplitude over width $\delta$. (c) Temperature-time paths plotted at different distances from the inlet within $x<\delta$ for the case where $\tau / t_{s}=150$ in (a) and (b), illustrating temporal oscillations at each location within the TRZ. (d) Width of the TRZ, $\delta$, as a function of oscillation period $\tau$ and channel spacing $d$ as indicated. Dashed lines (slope 2) are the expected analytic scaling in Eqn E1 and the squares indicate numerically derived values of $\delta$ obtained by fitting an exponential decay to the envelope of the $\left(T_{f}^{\prime}-T_{s}^{\prime}\right)$ oscillations in the TRZ, e.g., in (b). Thin horizontal lines are at $\delta=1$ and $10 \mathrm{~km}$. The vertical arrows indicate that for channel spacings of $d=10$ to $500 \mathrm{~m}$, thermal pulses with periods of $200 \mathrm{yrs}$ to $50 \mathrm{Kyrs}$ will give rise to TRZ widths of 1 to $10 \mathrm{~km}$ depending on $d$. 
https://doi.org/10.5194/se-2022-13

Preprint. Discussion started: 17 February 2022

(c) Author(s) 2022. CC BY 4.0 License.

Table A1. Material properties and constants used in calculations

\begin{tabular}{|c|c|c|c|}
\hline Name & Symbol & Value or range & Source/Comments \\
\hline Melt, grain density & $\rho_{\text {melt }}, \rho_{\text {grain }}$ & $2800,3300 \mathrm{~kg} / \mathrm{m}^{3}$ & Lesher and Spera (2015) \\
\hline Melt specific heat capacity & $c_{\text {pmelt }}$ & $1400 \mathrm{~J} /(\mathrm{kg} \mathrm{K})$ & Lesher and Spera (2015) \\
\hline Grain specific heat capacity & $c_{\text {pgrain }}$ & $1250 \mathrm{~J} /(\mathrm{kg} \mathrm{K})$ & Lesher and Spera (2015) \\
\hline Melt heat capacity per volume & $c_{\text {melt }}$ & $3.920 \times 10^{6} \mathrm{~J} /\left(\mathrm{m}^{3} \mathrm{~K}\right)$ & $c_{\text {pmelt }} \times \rho_{\text {melt }}$ \\
\hline Grain heat capacity per volume & $c_{\text {grain }}$ & $4.125 \times 10^{6} \mathrm{~J} /\left(\mathrm{m}^{3} \mathrm{~K}\right)$ & $c_{\text {pgrain }} \times \rho_{\text {grain }}$ \\
\hline Melt thermal conductivity & $\lambda_{m e l t}$ & $1 \mathrm{~W} \mathrm{~m}^{-1} \mathrm{~K}^{-1}$ & Lesher and Spera (2015) \\
\hline In-channel heat capacity per volume & $c_{f}$ & $3.920 \times 10^{6} \mathrm{~J} /\left(\mathrm{m}^{3} \mathrm{~K}\right)$ & $c_{f}=\varphi_{f} c_{\text {melt }}+\left(1-\varphi_{f}\right) c_{\text {grain }}=c_{\text {melt }}$ \\
\hline Out-of-channel heat capacity per volume & $c_{s}$ & $4.125 \times 10^{6} \mathrm{~J} /\left(\mathrm{m}^{3} \mathrm{~K}\right)$ & $c_{s}=\varphi_{s} c_{\text {melt }}+\left(1-\varphi_{s}\right) c_{\text {grain }}=c_{\text {grain }}$ \\
\hline Heat transfer coefficient & $k$ & $10^{-5}$ to $10^{1} \mathrm{~W} / \mathrm{m}^{3} \mathrm{~K}$ & this work (Appendix C) \\
\hline Channel volume fraction & $\phi$ & 0.01 to 0.2 & (e.g., Pec et al., 2017) \\
\hline Fluid-solid Nusselt number & $N u$ & 0.1 to 12.4 & for slow flows Handley and Heggs (1968) \\
\hline Constant in Eqn $\mathrm{C} 1$ & $\beta$ & 6 to 10 & Dixon and Cresswell (1979) \\
\hline Constant in Eqn C2 & $A$ & 2 to 6 & Dullien (1979) \\
\hline Separation of fluid-rich channels & $d$ & $10^{-1}$ to $10^{2} \mathrm{~m}$ & LeRoux et al. (2008) \\
\hline
\end{tabular}

Author contributions. This study was conceived, executed, and completed by Mousumi Roy

Competing interests. No competing interests are present.

Acknowledgements. This work benefited from conversations with L. Farmer, A. Clark, C. Havlin, B. Holtzman, and R. Carlson regarding western US evolution and melt-rock interaction. Funding sources for developing these ideas include: NSF EAR-0952325, EAR-2120812, an Aspen Center for Physics Fellowship, and a Women in STEM award from UNM-Advance. This study draws upon previously published observations and data/observations were not generated for this research. 
https://doi.org/10.5194/se-2022-13

Preprint. Discussion started: 17 February 2022

(c) Author(s) 2022. CC BY 4.0 License.

(c) (i)

\section{References}

Aharonov, E., Whitehead, J., Kelemen, P., and Spiegelman, M.: Channeling instability of upwelling melt in the mantle, J. Geophys. Research Solid Earth, pp. 20433-20 450, 1995.

Bo, T., Katz, R. F., Shorttle, O., and Rudge, J. F.: The melting column as a filter of mantle trace-element heterogeneity, Geochemistry, Geophysics, Geosystems, 19, 4694-4721., 2018.

Bodinier, J. L., Vasseur, G.and Vernie'res, J., Dupuy, C., and Fabrie's, J.: Mechanisms of mantle metasomatism - geochemical evidence from the Lherz orogenic peridotite, Journal of Petrology, 31, 597-628, 1990.

Bodinier, J.-L., Garrido, C. J., Chanefo, I., Brugier, O., and Gervilla, F.: Origin of Pyroxenite-Peridotite Veined Mantle by Refertilization Reactions: Evidence from the Ronda Peridotite (Southern Spain), Journal of Petrology, 49, 2008.

Carlson, R. W., Irving, A. J., Schulzec, D. J., and Jr, B. C. H.: Timing of Precambrian melt depletion and Phanerozoic refertilization events in the lithospheric mantle of the Wyoming Craton and adjacent Central Plains Orogen, Lithos, 77, 2004.

Dixon, A. G. and Cresswell, D. L.: Theoretical prediction of effective heat transfer parameters in packed beds, AIChE Journal, $25,1979$.

Dullien, F. A. L.: Porous Media: Fluid Transport and Pore Structure, Academic Press (New York), 1979.

Farmer, G. L., Fritz, D., and Glazner, A. F.: Identifying Metasomatized Continental Lithospheric Mantle Involvement in Cenozoic Magmatism from Ta/Th Values, Southwestern North America, Geochemistry, Geophysics, Geosystems, 21, 10.1029/2019GC008 499, 2020.

Gao, S., Rudnick, R. L., Carlson, R. W., McDonough, W. F., and Liu, Y.-S.: Re-Os evidence for replacement of ancient mantle lithospherebeneath the North China craton, Earth and Planetary Science Letters, 198, 307-322, 2002.

Handley, D. and Heggs, P. J.: Momentum and heat transfer mechanisms in regular shaped packings, Trans. Inst. Chem. Engrs., 48, T251, 1968.

430 Hauri, E. H.: Melt migration and mantle chromatography, 1: simplified theory and conditions for chemical and isotopic decoupling, Earth and Planetary Science Letters, 153, 1-19, 1997.

Havlin, C., Parmentier, E., and Hirth, G.: Dike propagation driven by melt accumulation at the lithosphere-asthenosphere boundary, Earth and Planetary Science Letters, 376, 20-28, https://doi.org/10.1016/j.eps1.2013.06.010, 2013.

Hirth, G. and Kohlstedt, D. L.: Rheology of the Upper Mantle and the Mantle Wedge: A View from the Experimentalists, Geophysical Monograph Series, 138, 83-105, 2003.

Holtzman, B. K. and Kendall, J.-M.: Organized melt, seismic anisotropy, and plate boundary lubrication, Geochem. Geophys. Geosyst., 11, Q0AB06, https://doi.org/10.1029/2010GC003296, 2010.

Hopper, E., Gaherty, J. B., Shillington, D. J., Accardo, N. J., Nyblade, A. A., Holtzman, B. K., Havlin, C., Scholz, C. A., Chindandali, P. R. N., Ferdinand, R. W., Mulibo, G. D., and Mbogoni, G.: Preferential localized thinning of lithospheric mantle in the melt-poor Malawi Rift, Nature Geoscience, 13, 584-589, 2020.

Keller, T. and Suckale, J.: A continuum model of multi-phase reactive transport in igneous systems, Geophys. J. Int., 219, 185-222, 2019.

Kenyon, P. M.: Trace element and isotopic effects arising from magma migration beneath mid-ocean ridges, Earth and Planetary Science Letters, 101, 367-378, 1990.

Kuznetsov, A. V.: An investigation of a wave of temperature difference between solid and fluid phases in a porous packed bed, International Journal of Heat and Mass Transfer, 37, 3030-3033, 1994.

Kuznetsov, A. V.: Comparison of the waves of temperature difference between the solid and fluid phases in a porous slb and in a semiinfinite porous body, International Communications in Heat and Mass Transfer, 22, 499-506, 1995a. 
https://doi.org/10.5194/se-2022-13

Preprint. Discussion started: 17 February 2022

(c) Author(s) 2022. CC BY 4.0 License.

(c) (i)

Kuznetsov, A. V.: An Analytical Solution for Heating a Two-Dimensional Porous-Packed Bed by a Non-Thermal Equilibrium Fluid Flow, Applied Scientific Research, 55, 83-93, 1995b.

Kuznetsov, A. V.: Analysis of heating a three-dimensional porous bed utilizing the two energy equation model, Heat and Mass Transfer, 31, 173-178, 1996.

Lamb, S., Moore, J. D. P., Smith, E., and Stern, T.: Episodic kinematics in continental rifts modulated by changes in mantle melt fraction, Nature, 547, 2017.

Lenoir, X., Garrido, C., Bodinier, J., Dautria, J., and Gervilla, F.: The recrystallization front of the ronda peridotite: Evidence for melting and thermal erosion of subcontinental lithospheric mantle beneath the alboran basin, Journal of Petrology, 42(1):141-158, 2001.

LeRoux, V., Bodinier, J., Tommasi, A., Alard, O., Dautria, J., Vauchez, A., and Riches, A.: The lherz spinel lherzolite: Refertilized rather than pristine mantle, Earth and Planetary Science Letters, 259, 599-612, 2007.

LeRoux, V., Bodinier, J.-L., Alard, O., and S.Y. O'Reilly, W. G.: Isotopic decoupling during porous melt flow: A case-study in the Lherz peridotite, Earth and Planetary Science Letters, 279, 76-85, 2008.

Lesher, C. E. and Spera, F. J.: Chapter 5 - Thermodynamic and Transport Properties of Silicate Melts and Magma, pp. 113-141, Elsevier, 2015 .

Menzies, M., Xu, Y., Zhang, H., and Fan, W.: Integration of geologygeophysics and geochemistry: A key to understanding the North China Craton, Lithos, 96, 1-21, 2007.

O’Reilly, S. Y., Griffin, W. L., Djomani, Y. H. M., and Paul: Are lithospheres forever? Tracking changes in the subcontinental lithospheric mantle through time, GSA Today, 11, 4-10, 2001.

Pec, M., Holtzman, B. K., Zimmerman, M. E., and Kohlstedt, D. L.: Reaction Infiltration Instabilities in Mantle Rocks: an Experimental Investigation, Journal of Petrology, 58, 979-1004, 2017.

Plank, T. and Forsyth, D. W.: Thermal structure and melting conditions in the mantle beneath the Basin and Range province from seismology and petrology, Geochemistry Geophysics Geosystems, 17, 2016.

Roy, M., Gold, S., Johnson, A., Orozco, R. O., Holtzman, B. K., and Gaherty, J.: Macroscopic coupling of deformation and melt migration at continental interiors, with applications to the Colorado Plateau, Journal of Geophysical Research, 121, doi:10.1002/2015JB012 149, 2016.

Rutherford, M.: Magma ascent rates, Reviews in Mineralogy and Geochemistry, 69, 241-271, 2008.

Saal, A. E., Takazawa, E., Frey, F. A., Shimizu, N., and Hart, S. R.: Re-Os isotopes in the Horoman peridotite: Evidence for refertilization?, Journal of Petrology, 42, 25-37, 2001.

Sakamaki, T., Suzuki, A., Ohtani, E., Terasaki, H., Urakawa, S., Katayama, Y., ichi Funakoshi, K., Wang, Y., Hernlund, J. W., and Ballmer, M. D.: Ponded melt at the boundary between the lithosphere and asthenosphere, Nature Geoscience, DOI: 10.1038/NGEO1982, 2013.

Schmeling, H., Marquart, G., and Grebe, M.: A porous flow approach to model thermal non-equilibrium applicable to melt migration, Geophysical Journal International, 212, 2018.

480 Schumann, T. E.: Heat transfer: a liquid flowing through a porous prism, Journal of the Franklin Institute, 208, 405-416, 1929.

Scott, D. R. and Stevenson, D. J.: Magma solitons, Geophys Res Lett, 11, 1161-1164, 1984.

Soustelle, V., A.Tommasi, Bodinier, J. L., Garrido, C. J., and A.Vauchez: Deformation and Reactive MeltTransport in the Mantle Lithosphere above a Large-scale Partial Melting Domain: the Ronda Peridotite Massif, Southern Spain, Journal of Petrology, 50, 1235-1266, 2009. 
https://doi.org/10.5194/se-2022-13

Preprint. Discussion started: 17 February 2022

(C) Author(s) 2022. CC BY 4.0 License.

(c) (1)

Spiga, G. and Spiga, M.: A rigorous solution to a heat transfer two-phase model in porous media and packed beds, International Journal of Heat and Mass Transfer, 24, 355-364, 1981.

Vauchez, A. and Garrido, C. J.: Seismic properties of an asthenospherized lithospheric mantle: constraints from lattice preferred orientations in peridotite from the Ronda massif, Earth and Planetary Science Letters, 192, 235-249, 2001.

Wallner, H. and Schmeling, H.: Numerical models of mantle lithosphere weakening, erosion and delamination induced by melt extraction and emplacement, International Journal of Earth Science (Geologische Rundschau), 105, 1741-1760, 2016.

Wang, H., van Hunen, J., and Pearson, D. G.: The thinning of subcontinental lithosphere: The roles of plume impact and metasomatic weakening, Geochemistry Geophysics Geosystems, 16, doi:10.1002/ 2015GC005 784., 2015.

Wenker, S. and Beaumont, C.: Can metasomatic weakening result in the rifting of cratons?, Tectonophysics, pp. 1940-1951, 2017.

Wiggins, C. and Spiegelman, M.: Magma migration and magmatic solitary waves in 3-D, Geophys Res Lett, 22, 1289-1292, 1995. 